\title{
SUBCUTANEOUS EMPHYSEMA COMPLICATING ASTHMA
}

\author{
BY \\ J. R. K. HENRY \\ From Hammersmith Hospital, London
}

(RECEIVED FOR PUBLICATION JANUARY 5, 1956)

Subcutaneous emphysema complicating asthma is a somewhat rare condition and when first met with rather an alarming one. Subcutaneous emphysema as a secondary manifestation of trauma of the chest wall, fracture of the orbit with escape of air from the nasal sinuses to the neck and thorax, or on occasion complicating tracheotomy or thoracentesis, is probably more common, and the mechanism whereby the air reaches the subcutaneous tissues is certainly more easily understood.

Elliott (1938) reports subcutaneous emphysema in a woman of 46 , developing at the onset of an asthmatic attack and followed two days later by a partial pneumothorax. In this case the subcutaneous emphysema was generalized and was not relieved until an incision was made over the chest wall; whereupon she deflated with a loud hissing sound. Field (1943) reports a case of a girl aged 4 years 2 months in whom subcutaneous emphysema complicated an acute attack of asthma. In this case the emphysema subsided, but 12 days later she developed a spontaneous pheumothorax and massive collapse.

\section{Case Report}

A girl aged 6 years 2 months was admitted to hospital as an emergency on October 22 with an attack of asthma. She had been having minor attacks of asthma, lasting approximately half-an-hour and subsiding without treatment, since the age of 16 months. During the last three months, the attacks had been more frequent and had lasted longer. The present attack had started on waking on the morning of admission; it was more severe than any she had had previously, and when she was seen was of some eight hours' duration.

Apart from frequent tonsillitis, she had had no previous illness, or eczema during infancy. Her paternal grandfather had asthma.

On admission she looked ill, and the lips were cyanosed. There was audible expiratory wheezing (temperature $100 \cdot 4^{\circ} \mathrm{F}$., respirations 60 per minute, pulse 160). On examination of the chest the movements were equal but poor, the trachea central. The breath sounds were harsh, and there were sibilant rhonchi predominantly expiratory over both lung fields.
She was given adrenaline, 4 minims subcutaneously, crystalline penicillin, 250,000 units six-hourly, 'gantrisin', 1 g. six-hourly, phenobarbitone, $\frac{1}{4}$ grain, and oxygen by mask immediately.

There was some improvement following the subcutaneous adrenaline, and it was thought that she would probably settle down and have a good night. However, she was restless and vomited three times during the night. The following morning her condition had obviously deteriorated, and on questioning she admitted to having had a severe pain in the left chest. The respiratory rate was now 70 per minute, pulse 170 per minute, and temperature $101^{\circ} \mathrm{F}$. The cyanosis was more marked and had an unusual maroon tinge. She was obviously in great distress.

On examination there was surgical emphysema extending around the neck, over the left chest and axilla, and down to the left flank. The heart appeared to be normal, the trachea was central, but the movement of the left chest was reduced and the breath sounds on the left almost absent.

A radiograph of the chest (Fig. 1) showed that both lungs were well expanded, and that there was marked surgical emphysema in the neck, the left axilla and in the mediastinum. She was given 'nepenthe', 8 minims, and put in an oxygen tent.

Her general condition improved almost immediately. Half-an-hour later her respiration rate had fallen to 50 per minute and four hours later was 20 per minute. The surgical emphysema did not increase in degree, but the following day had spread to the right chest. It then gradually subsided and in six days had entirely gone.

On discharge seventeen days after admission she was very well and the chest was clinically and radiologically clear (Fig. 2).

\section{Discussion}

It seems well established that for air to reach the subcutaneous tissues from the lungs in this type of case it must first reach the mediastinum. Once it has reached there it may proceed via the neck to any part of the body, as there is no anatomical barrier to stop its advance.

The mechanism within the lung has been well investigated by Macklin (1939) by introducing a 


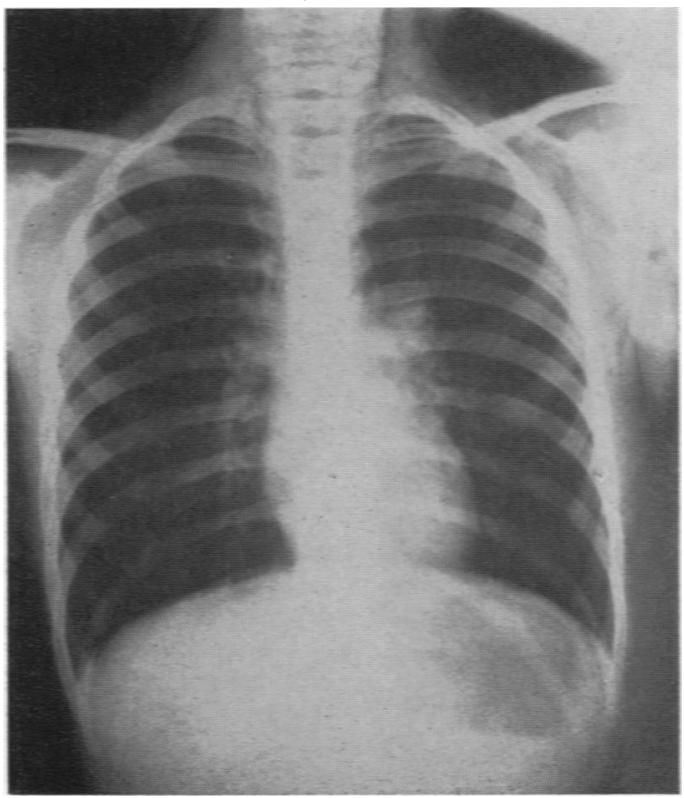

FIG. 1.-Chest radiograph taken on the morning after admission, showing marked surgical emphysema.

catheter into a region of an animal's lung and overdistending the alveoli. He found that the air leak was due to multiple and very fine ruptures in the alveolar bases, and that the escaping air travelled along artificial tunnels formed in the vascular sheaths. Further, within the lung it may take one or both of two routes: (1) To the mediastinum, from which there may be serious consequences, owing to an interference with the pulmonary blood flow due to the increased pressure in the perivascular sheaths at the root. It seems reasonable to suppose that this was the cause of the sudden increase of dyspnoea and tachypnoea of our patient, and that the aching pain complained of during the night was ischaemic in nature and secondary to a partial occlusion of the pulmonary blood flow. (2) The escaping air may equally track peripherally, and here form a bulla beneath the visceral pleura, and it seems reasonable too to suppose that rupture of a bulla so formed may be the cause of a spontaneous pneumothorax which occasionally complicates an acute attack of asthma without there being subcutaneous emphysema, or of the spontaneous pneumothorax which may occur at a variable time after the appearance of subcutaneous emphysema as in Field's case.

The prognosis of this condition seems to be good, and in a review of the literature by Rosenberg (1938), 18 cases of subcutaneous emphysema complicating

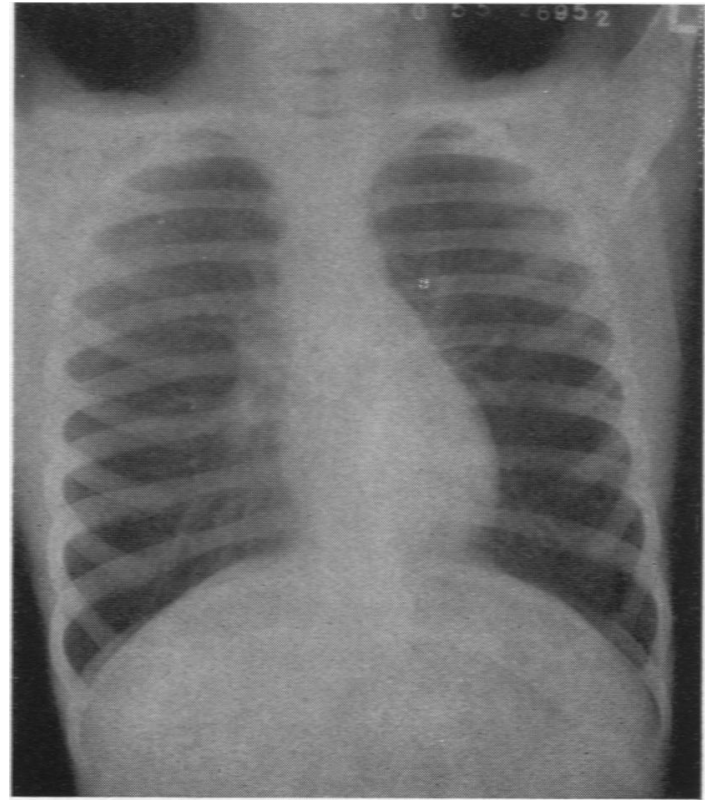

Fig. 2.-Chest radiograph 17 days after admission, showing complete absorption of the surgical emphysema.

asthma made a complete recovery, the emphysema disappearing in from two to 21 days. The ages of these patients ranged from 3 to 38 years.

The treatment of our case consisted of antibiotics. This is important because the artificial channels made by the air escaping from the ruptured alveoli make excellent pathways for bacteria to reach the lung parenchyma and the mediastinum. Secondly, sedation; 8 minims of 'nepenthe' intramuscularly was sufficient, and great improvement followed it. This immediately brings up the question of whether 'nepenthe' should be given to patients having an asthmatic attack; certainly in this type of case it seems to be indicated. Oxygen was given, partly as the cyanosis and respiratory distress warranted it, but also with the idea that if the subcutaneous air consisted mostly of oxygen it would absorb more quickly than if the nitrogen content were high. There was no need to remove the air artificially, as the emphysema was not massive and absorbed quickly. However, in cases where there is extreme subcutaneous emphysema, an incision is more likely to have the desired effect than attempting to aspirate. Finally, if the side from which the air is escaping can be localized, the induction of an artificial pneumothorax on that side, with the object of collapsing the lung and so preventing further escape of air from the alveoli would seem to be a logical form of treatment. 
Semmary

A case is reported of a girl aged 6 years 2 months who showed subcutaneous emphysema complicating an attack of asthma. The probable mechanism, likely complications and methods of treatment are discussed.
I wish to thank Dr. Charles Newman for permission to report this case, and for the help and encouragement he gave me in preparing the paper.

Elliot, R. W. (1938). Lancet, 1, 1104.

Fiedd, C. E. (1943). Archives of Disease in Childhood, 18, 197.

Macklin, C. C. (1939). Arch. intern. Med., CA, 913.

Rosenberg, L. and Rosenberg, J. (1938). Amer. J. med. Sci., 195, 682. 